\title{
The Origins of Empathic Concern ${ }^{1}$
}

\author{
Carolyn Zahn-Waxler ${ }^{2}$ and Marian Radke-Yarrow
}

National Institute of Mental Health

Recent developments in research cast doubt on early conceptions of young children as primarily egocentric and uncaring of others' needs. Studies reviewed indicate a broad range of social competencies children bring to their interpersonal relationships. As early as 2 years of age, they show (a) the cognitive capacity to interpret, in simple ways, the physical and psychological states of others, (b) the emotional capacity to experience, affectively, the state of others, and (c) the behavioral repertoire that permits the possibility of attempts to alleviate discomfort in others. Both temperament and environment may contribute to individual differences in concern for others. Early socialization experiences that lead to adaptive and maladaptive patterns of responsiveness to others' needs are described. Examples of environmental risk conditions include parental depression, marital discord, parental maltreatment. Implications of this work for broadening existing conceptualizations of empathy and related prosocial orientations are addressed.

Human beings are strongly motivated to be connected to others as well as to retain independence and autonomy. A major developmental task that persists throughout their lifespans relates to the balance and integration of these two sets of needs. A number of constructs have been used to characterize connection to others. These include terms such as attachment, warmth, emotional availability, dependency, nurturance, succorance, inter-

${ }^{1}$ This work was supported by the National Institute of Mental Health and the John D. and Catherine T. MacArthur Foundation, Research Network on the Transition from Infancy to Early Childhood. Portions of this work were presented at an invited symposium on Empathy in Infancy and Later Development, American Association for the Advancement of Sciences, New Orleans, 1990. We would like to thank Jean Mayo for manuscript preparation.

${ }^{2}$ Address all correspondence to Carolyn Zahn-Waxler, Laboratory of Developmental Psychology, Building 15-K, National Institute of Mental Health, Bethesda, Maryland 20892. 
personal commitment, caring, and compassion, to name just a few. Considerable research has focused on these dimensions in the context of adolescent and adult love relationships, or as an important feature of caregiving with corresponding implications for the welfare of the young. Except for research on attachment, less effort has been directed toward understanding ways in which children establish and maintain positive connections, especially as this pertains to their capacity to care for others. In this article, we explore one aspect of social connection: namely, the early development of empathy. This emotion is described by some as at the center of what it means to be fully human. The construct of empathy is particularly complex. Theoretical explanations can be traced historically to the ideas of early aesthetic, sociological, social-psychological, developmental, and counseling/ psychotherapy writers (see review by Gladstein, 1984).

Empathy has many definitions that derive, in part, from its diverse theoretical heritage (Eisenberg \& Strayer, 1987). At its core, however, empathy refers, in various ways to the experiencing of another's affective or psychological state and has both affective and cognitive components. The cognitive component involves apprehending or understanding the other person's experience, i.e., imagining oneself in the place of the other so as to know what the other feels or senses. In some conceptualizations of the affective component, a strict or near match of another's emotions is required (e.g., sadness in response to another's sorrow, anger in response to another's anger). The concept of contagion of emotion also is relevant here, e.g., as in "catching" the fear of another person. Sullivan (1947) was one of the first to describe this phenomenon in the motherchild dyad, indicating ways in which even infants pick up on the caregiver's affective state. In other conceptualizations of the affective dimensions, feelings of empathic or sympathetic concern for the other person in distress are emphasized. Eisenberg and her colleagues distinguish conceptually between empathy and sympathy, though they indicate the difficulty of distinguishing empirically between the two (Eisenberg, Fabes, Miller et al. (1989a). In this view, empathy is an emotional response that is congruent with and stems from the apprehension of another's emotional state or condition. Sympathy, which may stem from empathy, is defined as a vicarious emotional response to similar external conditions, which consists of feelings of sorrow or concern for others. Both empathy and sympathy are though to differ from personal distress, defined as a self-focused, aversive reaction to another's state and experienced as anxiety or distress. Empathy is though to be a process that generally induces sympathy or personal distress.

From a developmental perspective, the origins of these different patterns of vicarious emotional response and their linkages to different 
behavior patterns are of special interest. We review here theories and research relevant to the early emergence of these phenomena. We emphasize not only the affect that is evoked by others' distress, but the positive action patterns children first show in response to victims in distress (e.g., helping, sharing, comforting behaviors). Such behaviors intended to alleviate the suffering of others, traditionally have not entered into conceptual or operational definitions of empathy. We would argue that this decision needs to be reconsidered. First, we describe briefly the context that defines the significance of this area of inquiry, followed by review of theories and empirical research relevant to the early emergence of empathic concern for others.

Empathy has only recently re-emerged as a topic of research interest meriting scientific inquiry. For many years, it was ignored for two main reasons: (1) Prevailing theories did not deem it an important aspect of human nature and (2) adequate operational definitions and rigorous research methods for studying the phenomenon were difficult to establish. Advances both in theories and in behavioral and biologically based measurement approaches have done much to expand work in this area. Much of early conceptualization about human nature was rooted in underlying belief systems, grounded in centuries of arguments by philosophers and moralists, that individuals were basically selfish and self-serving. These beliefs, in turn, were transformed into twentieth century psychoanalytic, psychological and sociobiological theories emphasizing the unlikelihood that empathic concern and caring actions on behalf of others in need could reflect a primary and ultimate goal of human behavior.

In the decade of the $1980 \mathrm{~s}$ this issue has been played out most prominently in research and debates by two teams of investigators (Batson and colleagues and Cialdini and colleagues). The latter argue that virtually all prosocial behaviors can most parsimoniously be explained by egoistically based motives - i.e., that prosocial behaviors are ultimately motivated by desire for reward, fear of punishment, or the need to reduce selfexperienced aversive arousal in response to the distress of another. Batson, in contrast, argues for a pluralism of prosocial motives, resulting from aitruistic or empathically based concerns where the ultimate goal sometimes is (concern for) the welfare of the other. In a series of elegant and complex studies of young adults, Batson provides a plausible case for the possibility that, under some conditions, altruism and prosocial behavior may be empathically based, and do not simply emanate from rewardpunishment contingencies or efforts to reduce personal distress. But alternative explanations are always possible and the controversy continues (e.g., see Batson et al., 1989; Batson et al., 1988: Carlson \& Miller, 1987; Cialdini, Shaller, Houlihan, Arps, Fultz, \& Beaman, 1987). 
Technological advances have created new opportunities for more sophisticated measurement of concern for others. Initially research was dominated by self-report procedures in which subjects indicate what they are feeling or thinking in relation to another's experiential state (a procedure not conducive to assessments of young children). It is now possible to obtain more objective measures of the "subjective" nature of this phenomenon via measures of psycho-physiological arousal (e.g., HR, GSR) Eisenberg, Fabes, Shaller, \& Miller, 1989b). It is also now possible to code facial affect using neuro-anatomically based systems that examine facial musculature, as well as to code vocal affect in terms of acoustic patterns derived from spectral analyses. These approaches would be consistent with a recent neuroscience perspective (Brothers, 1989) in which empathy is viewed as a high-level construct that can be used to bring together neural, clinical, and behavioral data. In this view, some aspects of neural activity are thought to exist, and to be shaped, in part, by the need for rapid, accurate evaluation of the motivations of others (in humans and in other species).

Empathy is viewed as critical to all social processes in the interactionist perspective of Cooley (1926) and role-taking theory of Mead (1934). It may be crucial to the development of insight, for we may come to see ourselves through eyes of others via empathy. Empathy is considered an important condition for effective therapeutic intervention in psychotherapy. In theories of moral development, it is often viewed as a fundamental motivator in eliciting altruism and inhibiting aggression. That is, if persons vicariously experience the distress that they have caused to others because of their aggression, they will be less likely to continue to hurt others and more likely to help them. Indeed, research does demonstrate that empathy and aggression are inversely related (Miller \& Eisenberg, 1988), at least under some conditions.

Uniting these views is the notion that empathy is a fundamental building block for positive growth and development. It occurs in the context of the complex, fluid and clearly interdependent social relatedness of human beings. Concern for others is a sign of mental health, while disturbances in empathy are evident in mental and emotional problems (American Psychiatric Association, 1987). Infantile autism and schizophrenia are marked by diminished empathy and difficulty in forming basic emotional bonds. Some personality disorders are characterized by egocentrism, selfabsorption, and narcissism. Antisocial behavior patterns are marked by lack of regard for others, inability to feel remorse, and even the derivation of pleasure from the distress of others. Overdeveloped empathy has been linked to still other kinds of emotional problems. For example, interdependencies between individuals may become too fluid such that one 
consistently experiences another's problems as one's own, at the expense of self-actualization and development. Such differences among individuals raise questions both about biological underpinnings and environmental conditions that contribute to both adaptive and maladaptive patterns.

\section{THEORIES OF EARLY EMPATHY}

Children begin to display a moral sense during the second year of life: Adherence to standards become important, empathy is emerging, and anxiety in response to social disapproval is one emotion that may underlie morality (Kagan \& Lamb, 1987). The second year of life is emphasized by emotions theorists as the period during which higher-order, self-conscious, "moral" emotions reflecting some capacity for role-taking emerge (e.g., empathy, guilt, shame) (Campos, Barrett, Lamb, Goldsmith, \& Stenberg, 1983; Darwin, 1872; Izard, 1977, Shott, 1979). Some socialization approaches (Emde, Johnson, \& Easterbrooks, 1987; Yarrow, Scott, \& Waxler, 1973; Zahn-Waxler, Radke-Yarrow, \& King, 1979); also focus on the early years and the role of the environment in shaping individual differences in children's patterns of responsibility at this time. Parents begin to assume intentionality in their children, to hold them accountable for their actions, and to expect interpersonally appropriate behavior.

Hoffman (1975) has elaborated a comprehensive theory of early moral development as a joint function of cognitive, affective, and social processes. He postulates a biological preparedness for empathy. The reflexive crying of infants in response to the crying of other infants is viewed as a primitive precursor of empathic arousal. It is an innate, hardwired response connecting us as social beings to the emotional plights of others. During the second year of life, children begin to differentiate self and other, and their emotional involvement in another's distress becomes less likely to reflect a reflexive fusion of self and other. Children come to understand that others are separate beings, and affective arousal experienced in relation to others' distress begins to become transformed from personal selfdistress to sympathetic concern for the victim. Comforting interventions also are hypothesized to emerge during this period. In this view, rudimentary forms of both empathy and guilt develop during the second year off life, and show similar developmental courses (Hoffman, 1982). Empathy occurs in response to distress in a victim, whether this distress is caused or witnessed by the child. Interpersonal guilt results from the conjunction of an empathic response to someone's interpersonal distress and awareness of being the cause of that distress. 
These theories are incompatible with psychoanalytic (Freud, 1958) and social-cognitive (Piaget, 1933/1965) theories, in which young children were seen as primarily egocentric, helpless and socially inept. Both conscience and compassion were hypothesized to evolve during middle childhood, dependent upon (a) slowly maturing cortical structures required for reflective self-awareness and sensitivity to the internal states of others and (b) resolution of emotional conflicts within the family in which aggressive/sexual impulses were eventually subdued. These views of young children as empathic also are counter to most socio-biological perspectives, in which the selfish nature of humans is emphasized (e.g., Dawkins, 1976) or altruism is considered to be ultimately self-destructive (Wilson, 1975). Some more recent neuroscience and socio-biological perspectives place greater emphasis on empathy as a mediator of adaptive social connectedness, and more specifically, of behavioral concern for the welfare of others (e.g., Brothers, 1989, MacLean, 1985).

MacLean (1985) proposes that the capacity for empathy emerged in conjunction with the evolution of mammals 180 million years ago in late Triassic times. Mammals are warm-blooded creatures who nurture, nourish, and protect their young, as opposed to reptilian, cold-blooded creatures who destroy and abandon their offspring. In his view, when mammals opted for "a family way of life," the stage was set for exposure (and responsiveness) to highly distressful expressions of pain, separation, and suffering in others. Such stimuli provide the bases for empathy. In MacLean's analysis of the mammalian triune brain, he proposes interconnections of the limbic system with prefrontal cortex, linked originally to parental concern for the young and from which a broader sense of responsibility eventually emerged. He argues that, through the higher reaches of the brain, parental concern for the young may generalize to other members of the species. Such speculations are thought-provoking. They require us to consider from an evolutionary perspective, how deeply embedded and innate the capacity for empathy may be, both as a component of human nature and as a quality we may share with some other animals. It also raises questions about the processes by which more reflexive patterns of concerned responding may become transformed into more purposeful, planful action patterns. We consider this issue next, in the context of research on early human development.

\section{RESEARCH WITH YOUNG CHILDREN}

From birth onward, infants are responsive to emotions in others. Contagion (Sagi \& Hoffman, 1976; Simner, 1971) and imitation of others' 
emotions (Field, Woodson, Greenberg, \& Cohen, 1982; Meltzoff \& Moore, 1977 ) are present even in the first days of life, suggesting a biologically based predisposition. Infants as young as 10 weeks discriminate between mothers' presentations of happy, sad, and angry faces and match their mothers' emotions under some conditions (Haviland \& Lelivica, 1987). Infants' responses to mothers' expressions indicate more joy during a joy expression and more sadness, anger, and gaze aversion during a sadness expression (Termine \& Izard, 1988). Other research (Cohn \& Tronick, 1983; Cohn, Campbell, Matias, \& Hopkins, 1990) also documents infants' responsiveness to the affective states of caregivers and focuses on the negative arousal induced in infants by maternal depression.

The beginnings of representational thought during the second year of life (Bruner, 1972; Piaget, 1962) and the use of symbols (e.g., McCall, 1979; Nicolich, 1977) have implications for children's abilities to imagine and infer others' perspectives (Butterworth, 1980), and feelings (Rheingold \& Emery, 1986). During this period, self-recognition and self-other differentiation develop (e.g., Amsterdam, 1972; Bertenthal \& Fischer, 1978; Lewis, Sullivan, Stanger, \& Weiss, 1989; Watson \& Fisher, 1977). Children begin to talk about emotions, and to describe others' internal states as well as their own (Bloom, Lightbown, \& Hood, 1975; also see review by Bretherton, Fritz, Zahn-Waxler, \& Ridgeway, 1986). Both these and related aspects of self-development (e.g., Lewis et al, 1989; Stipek, Gralinski, \& Kopp, 1990) may be necessary preconditions for the expression of self-conscious and moral emotions.

There is also some evidence for the emergence of positive social behaviors of helping, sharing, and cooperation during the second year of life (Eckerman, Whatley, \& Kutz, 1975; Rheingold, Hay, \& West, 1976; Ross \& Goldman, 1977). Still earlier processes of attachment and bonding with the caregiver may prepare the child for later empathic connections through the complex interplay of sharing and exchange of emotions, as well as cooperation and turn-taking in social interactions between parent and infant (Stern, 1985; Trevharthen, 1989). Prosocial behavior, in response to another's distress, occurs in preschool-age children (e.g., Eisenberg-Berg \& Lennon, 1980; Radke-Yarrow \& Zahn Waxler, 1976; Yarrow, Scott, \& Waxler, 1973), but base rates are low. Caplan and Hay (1989) studied 3to 5-year olds' responses to distressed peers. Children's low frequencies of prosocial responding appeared to reflect their expressed beliefs that it is not their role to help when competent adult caregivers are present, rather than their lack of capacity.

In summary, even very young children bring a broad range of competencies to their relationships with others. As early as 2 years of age they show (a) the cognitive capacity to interpret the physical and psychological 
states of others, (b) the emotional capacity to experience affectively the states of others, and (c) the behavioral repertoire that permits the possibility of trying to alleviate discomfort in others. Two longitudinal studies suggest that the integration of these capacities begins between the ages of 1 and 2: Children develop empathic concern for others in distress that becomes translated into prosocial actions on their behalf. Radke-Yarrow and Zahn-Waxler (1984) trained mothers to observe and report on their 1- to $2 \frac{1}{2}$-year olds' responses to naturally occurring distress in others, including both distress that children witnessed as bystanders and distress they caused. Mothers also were trained to simulate distress emotions and record their children's reactions. In more recent work, these procedures were again carried out and children's responses to simulations also were videotaped and coded by independent observers (Zahn-Waxler, Radke-Yarrow, Chapman \& Wagner, 1990).

Prosocial interventions appear at the beginning of the second year of life and increased in frequency throughout this year, taking more varied forms as children grew older (Radke-Yarrow \& Zahn-Waxler, 1984; ZahnWaxler \& Radke-Yarrow, 1982; Zahn-Waxler, et al., 1990). The first prosocial actions are mainly physical (hugs, pats) and sometimes appear to provide self-comfort (or reduction of personal distress) as well as relief to the victim. By the end of the second year of life, prosocial behaviors have become more differentiated as well as more appropriate to the victim's needs. Children are observed to help, share, provide physical comfort, provide verbal sympathy, protect, and defend victims in distress. Often the prosocial behaviors are accompanied by expressions of concern or worry and/or by attempts to comprehend the nature of the distress. For example, it is not uncommon for children to look sad and ask what is the matter, if they see a mother injure herself, hear an infant crying for its bottle, or hear the dog yelping because someone has stepped on its tail.

Figure 1 illustrates several components of an empathic prosocial pattern in a 21-month-old's set of responses to his mother's simulation of sadness. In this complex sequence of events, he (1) attends to the mother's sadness; (2) peers into her face to determine what is wrong (making verbal inquiries as well); (3) tries to distract the mother with a hand puppet; (4) looks concerned and beseeches the experimenter to come to the rescue; and (5) then gives the mother a hug while making consoling sounds and sympathetic statements.

Comforting interventions are directed first toward caregivers and other family members and only later to unfamiliar others, which is not unexpectable. Of interest, however, is the observation that young children do show emotional concern and cognitively explore the distresses of unfamiliar 
others, even though they are unlikely to try to help. Children's prosocial behaviors increase with age, whether they have caused distress (e.g., by stepping on the dog's tail) or simply witnessed the distress as a bystander (e.g., mother gets splattered with grease). This illustrates children's growing tendencies to repair harms created as well as to intervene as bystanders when others are in need. This is consistent with Hoffman's (1982) view that empathy and guilt reflect conceptually related feelings of responsibility and follow parallel developmental trajectories. While empirical evidence supports this position, it needs also to be noted that children sometimes are able, as well, too discriminate circumstances in which they cause distress vs. simply observe others in distress. When they cause distress, they also sometimes show less concern, more aggression, more enjoyment of the others' distress, and less curiosity about why the problem exists (perhaps because they already "know").

As children move from the end of the first year to the beginning of the third year of life, they gradually appear to experience less personal distress in response to others' distress (Zahn-Waxler \& Radke-Yarrow, 1982) and more sympathetic concern (Zahn-Waxler et al., 1990). Affective arousal becomes more modulated. From a developmental perspective, decrease in aversive arousal may (necessarily) precede the ability effectively to care for and comfort others. This speculation is consistent with an organizational approach to understanding early developmental changes in social-emotional functioning more generally in the second year of life (Cicchetti \& Schneider-Rosen, 1986). During this time children are moving from states of diffuse and undifferentiated arousal to more integrated, organized, emotionally regulated response patterns. With differentiation, children develop greater flexibility in responding to the surroundings and become able to use various means of obtaining a desired goal. With regard to empathy in particular, as children begin to differentiate self from other during the second year of life (and hence to better "understand" that the distress is within the other, not the self), they become more self-regulated and other-oriented in the face of another's distress, as well as more purposeful and planful in their action patterns.

One task for future research involves attempts to identify more precisely the emotional experiences and psychophysiological arousal experienced by these young children during this transition period. We have observed that a considerable variety of emotions are expressed by very young children in the context of another's distress. These run the gamut from surprise, to fear and wariness, to concern and sadness, to being so overwhelmed by the other's distress that the child withdraws and "shuts down." Expressions of anger directed toward perceived perpetrators of distress can be observed. (These may reflect a form of empathy that is not 

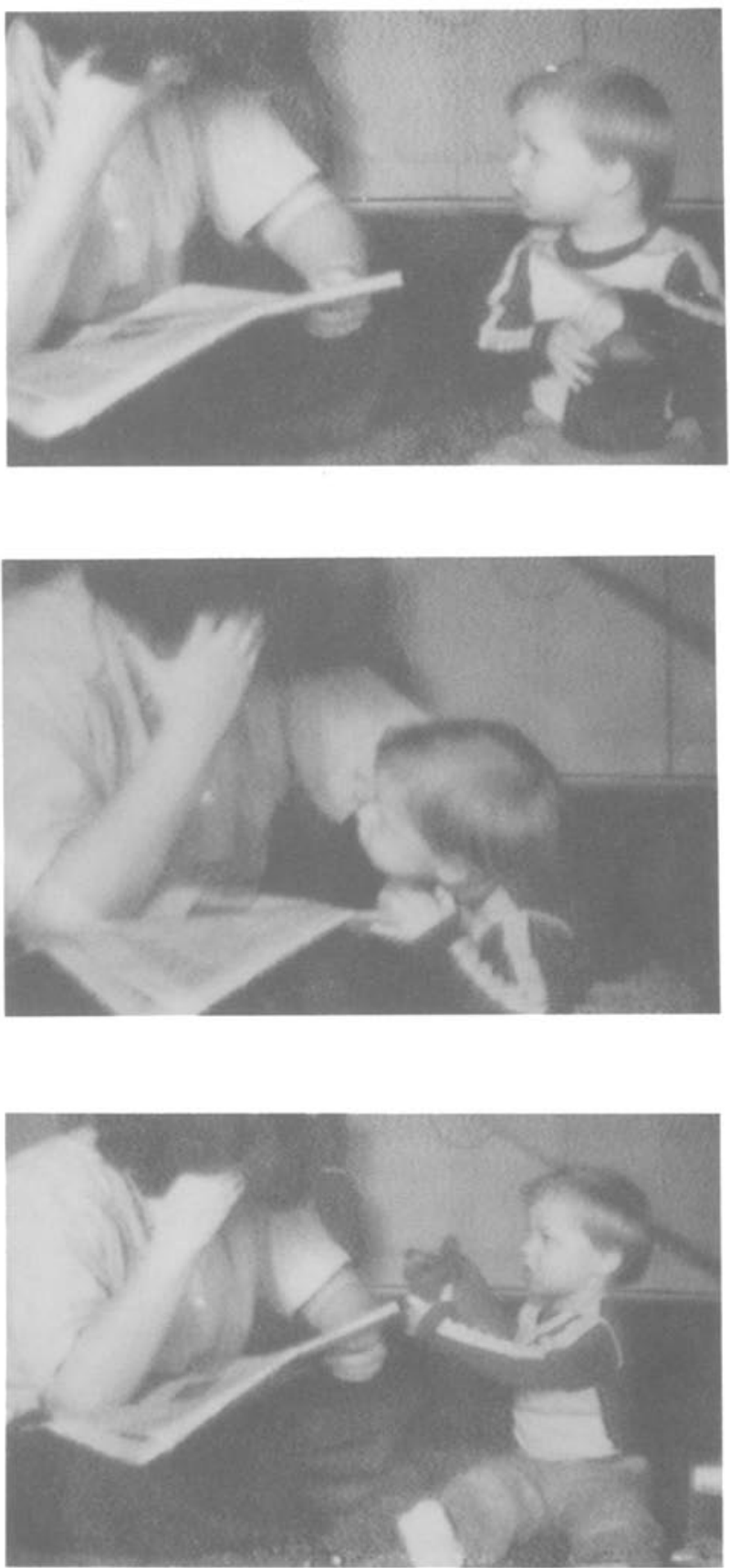

Fig. 1. Several components of an empathic, prosocial pattern in a 21month-old's set of responses to his mother's simulation of sadness. Parts 1 through 5 explained the main text. 

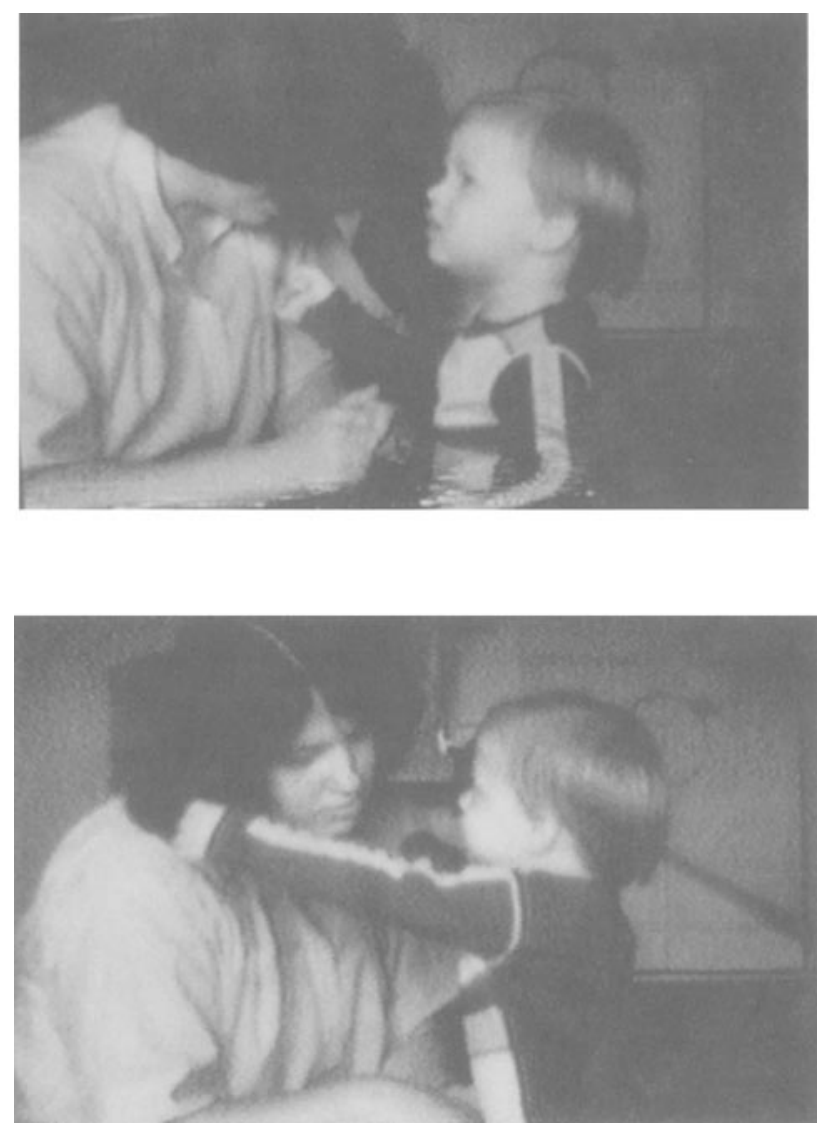

Fig. 1. Continued.

captured well by any of the more literal coding systems that do not take intentionality or motivation into account.) It is also possible to ohserve interest and possible amusement. Positive affect may have different meanings (e.g., a "nervous" smile vs. real enjoyment of another's distress). Moreover, sometimes children smile at distressed individuals in apparent efforts to cajole them out of a bad mood or negative state. Sometimes children appear to "try on" the other's emotional experience (e.g., wincing in response to another's pain, or grabbing their own leg when another has just bumped into a chair). Hoffman (1975) describes this as motor mimicry, which he views as a form of empathic affect arousal that developmentally follows reflexive crying. These and other forms of automatic or involuntary arousal 
undoubtedly interact in complex ways with the development of a cognitive sense of others and early socialization experiences, to produce different types of empathically based behavior patterns.

\section{SOCIALIZATION OF EMPATHIC BEHAVIOR PATTERNS}

In addition to early developmental changes in caring behaviors toward others, there is also evidence for stable, individual differences (Cummings, Hollenbeck, Iannotti, Radke-Yarrow, \& Zahn-Waxler, 1986), which raises questions concerning both biological and experiential factors contributing to these differences. We examine next one significant source of influence, namely, socialization. The family environment frames each child's first experiences with its own and others' distress, and how these distresses are handled. It provides the first occasions for children's own empathic reactions and experiences with the compassion of their caregivers. Variations in caregiver sensitivity and nurturance are well documented, as are differences in parents' modeling of altruism toward others and in their discipline and teaching techniques that mav dull or heighten the child's emotional and cognitive awareness of other's problems.

Some of these parental behaviors have been found to relate to children's prosocial behavior patterns (see review of socialization influences by Radke-Yarrow, Zahn-Waxler, \& Chapman, 1983). For example, mothers observed to be affectionate and sensitive in interaction with their children in the first years of life had children who were also more likely to express concerned behavior patterns. Moreover, mothers who explained clearly, and with considerable conviction, the importance of kindness, of regard for the rights of others, and of restraint from harming others had the more concerned children (Zahn-Waxler et al., 1979). Similarly, in an experimental training study of middle-class, preschool-age children (Yarrow, Scott, \& Waxler, 1973), adult nurturance, generalized modeling of prosocial behavior, and use of explanations resulted in more autonomous, enduring, sympathetic orientations.

Research on the correspondences between empathy in parents and their offspring does not yield a uniform picture. Some studies indicate that more empathic parents have more empathic children and that this is particularly true for mothers and daughters (see review by Zahn-Waxler \& Smith, in press; also see Eisenberg et al., 1989b). But this is not always the case (e.g., Strayer \& Roberts, 1989). The search for socialization antecedents of empathic behavior in children must take into account a variety of parenting practices that include how parents handle children's negative, as well as positive, emotions and behaviors. For example, mothers' attempts 
to inhibit aggression in 5-year-olds predicted empathy when these children were adults, over 25 years later (Koestner, Franz, \& Weinberger, 1990). Parental efforts to prevent aggression often include attempts to explain to the child the negative outcomes for others of his/her harmful acts, which is a form of perspective-taking or role-taking (i.e., helping the child to imagine being in the place of the other). This association, in the Koestner $e t$ al. study, between parental inhibition of aggression and later empathy was true for female, but not male, offspring. Other studies suggest that greater socialization efforts are exerted toward girls to engage in (role-appropriate) behaviors that include nurturance, warmth, empathy, connection, compassion, and caring (see review by Zahn-Waxler, Cole, \& Barrett, 1991). Moreover, girls are viewed more harshly than boys if they fail to express empathic behavior patterns (Barnett, McMinimy, Flouer, \& Masbad, 1987). Such studies raise the larger question of whether socialization experiences that encourage more extreme reactions may reflect conditions of risk that lead to maladaptive outcomes.

\section{The Role of Parental Depression}

We view the early years of life as a time when the child is at particular risk, not only for being drawn into parental problems, but also for feeling that they are at fault. Empathy and guilt appear to develop in contexts that share an important common feature of someone else being in distress. They differ mainly in terms of whether or not the child has caused the distress. Many of the first emotions and behaviors that children show in these two situations are very similar. Since it is not always easy for young children to distinguish between problems they cause and observe (especially when they have not "intended" a harm), empathy and guilt can become confused. This may be a time when children are particularly vulnerable to feelings of responsibility for problems they did not create. Children who overempathize with very distressed, unhappy parents, for example, may themselves experience too much distress, treat others' problems as their own, and confuse boundaries between self and significant others. Such conditions would be expected to interfere with the development of autonomy and mature social interaction patterns with peers, as children remain preoccupied with problematic parental functioning.

There are some indications that young children of depressed caregivers may experience too much empathy and too many feelings of responsibility (Zahn-Waxler, Kochanska, Krupnick, \& McKnew, 1990; Zahn-Waxler \& Kochanska, 1990). Later in development, this could result not only in overinvolvement in other's problems, but also in reactance, am- 
bivalence, and avoidance of others in distress as individuals struggle against being overwhelmed by the pain and suffering of others. Beardslee and colleagues, in work with adolescents of depressed caregivers, have found that girls with extremely high interpersonal sensitivity (presumably learned in the family context) have particularly poor peer relations (Beardslee, Schultz, \& Selman, 1987). At the same time, it is possible to identify adolescents of depressed parents who are particularly mature and responsible in ways that appear adaptive rather than dysfunctional (Beardslee \& Podorefsky, 1988).

\section{The Role of Marital Discord}

Parental depression often co-exists with marital disharmony, another environmental condition that may influence children's emotional involvement in the needs of others. One theme in the literature on divorce and marital discord concerns the precocious and unrealistic sense of responsibility that children assume for parents' problems, as well as more actingout problems (Emery, 1982). Even very young children can become participants in verbal arguments between parents. In one study in which 2-year-olds from high-conflict and low-conflict homes were compared (Cummings, Zahn-Waxler, \& Radke-Yarrow, 1981), children whose parents argued frequently were especially likely to become angry and distressed themselves. And they intervened more than children from low conflict homes by trying to get parents to stop, to comfort one of them, or to get them to make up. Thus, even 2-year-olds begin to play the role of mediator or peacemaker. The high negative arousal that accompanies these interventions indicates that they are qualitatively different from the more normative, regulated patterns we have observed in many children. There is already some evidence that these patterns of arousability show some stability over several years time (Cummings, Zahn-Waxler, \& RadkeYarrow, 1984).

Research from the literature on marital discord and parental depression suggests one possible model for understanding how patterns of depressive affect, and more general difficulty in negotiating and maintaining harmonious relations, repeat across generations. In attributional theories, adult depression is characterized by overwhelming feelings of both helplessness and responsibility. The fact that young children with an emotionally distressed caregiver often cannot help the parent may lead to feelings of helplessness and failure. The belief, however, that they can create change may lead to feelings of responsibility that occasionally are reinforced when 
the child succeeds in making the parent feel better. Thus, young children could experience depression-like "symptoms" of helplessness and responsibility early and repeatedly as a consequence of empathic overinvolvement. If these patterns continue over time and generalize to other relationships, they may make conflict resolution difficult and pave the way for later emotional problems.

\section{The Role of Parental Maltreatment}

Parental abuse of the young is an environmental condition associated with general maladaptive outcomes for children. For many reasons we would expect it to affect the nature of empathy in these children. The work of Main and her colleagues (e.g., Main \& Goldwyn, 1984) has focused on the quality of the parent-child attachment relationship in maltreating families, and its implications for the development of subsequent relationships. The security of this relationship, as well as the maltreatment per se (i.e., the aggression that is modeled and experienced), will influence how children experience and treat others and the kinds of problems they develop. There is increasing evidence that children who are securely attached to caregivers are better able to empathize and share with others (e.g., Matas, Arend, \& Sroufe, 1978; Teti \& Ablard, in press).

Studies of maltreated toddler and preschool-age children demonstrate the poor quality of the attachment relationships with their caregivers (Cicchetti \& Schneider-Rosen, 1986). They also suggest that the inadequate, hostile, and unempathic caregiving of maltreating parents, dramatically apparent in clinical work (Haynes-Seman, 1987), may affect children's early developing peer relations. In three observational studies, abused youngsters not only caused distress and behaved more aggressively toward playmates, but also showed more inappropriate responses to a peer's distress. Abused children are more likely to withdraw or aggress toward a distressed peer, and are less likely to show concern or offer help (Howes \& Eldridge, 1985; Klimes-Dougan \& Kistner, 1990; Main \& George, 1985). Thus, even in early interactions with playmates, many of these children appear to adopt behavior patterns similar to those of their maltreating parents. These behaviors are likely to elicit rejection by peers, which may in turn, have long-term implications for the quality of their social relations. Peer rejection is a consistent early predictor of later interpersonal difficulties, behavior problems, and psychopathology. 


\section{Interpretation of Individual Differences in Empathy}

Individual differences in children's concern for others thus may result from different environmental conditions and learning experiences. It is also possible that aspects of empathy are heritable. Adult monozygotic $(\mathrm{mz})$ and dyzygotic (dz) twins have been compared on empathic concern (Matthews, Batson, Horn, \& Rosenman, 1981) and altruism (Rushton, Fulker, Neale, Nias, \& Eysenck, 1986). Both studies indicate greater concordance or similarity of responding in $\mathrm{mz}$ than in $\mathrm{dz}$ twins, supporting the possibility of a heritability component. The measurements are based solely on selfreports, and nonbiologically based differences could also contribute to concordance patterns. Important questions are raised, however, that might be investigated with other methods and with much younger organisms, before years and even decades of socialization influences come to overlay possible innate differences. Current ongoing observational research with young $\mathrm{mz}$ and $\mathrm{dz}$ twins (Zahn-Waxler, Robinson, \& Emde, 1991) begins to provide modest support for the hypothesis that some features of empathy are heritable.

It is likely that research with young children will provide evidence for the roles of both nature and nurture in young children's empathy. Research done thus far supports Hoffman's (1975) theory and calls into question early psychoanalytic and social-cognitive theories in which all young children were viewed mainly as impulse-ridden, self-centered, and motivated to conform through fear. There has been a tendency to oversimplify the construct of empathy. Some see it as solely good, reflecting the "bright" side of human nature, and as a polar opposite to destructive, aggressive impulses. We know that both caring and hostile feelings can be functional and dysfunctional. They reside in all of us, to greater or lesser degrees; our brains and bodies are exquisitely well-prepared to make rapid shifts between compassionate and destructive actions, or to engage in them simultaneously. Soldiers in combat, for example, may take time, in the midst of danger, to rescue infants and children. Or mothers caring for their young will aggress vigorously to protect their child against an intruder.

Traditionally, much of the work on patterns of empathy and responsibility has been done within the context of theories of moral development, more than theories relevant to social competence and dysfunction. Moreover, developmental transitions and universal processes have been emphasized more than individual differences. Interpretations about the latter are discomforting, for they involve what may be seen as value judgments, i.e., concluding that certain individuals are more uncaring and less responsible in interpersonal relations than others, and that they show 
deviant patterns of empathy. And we are understandably reluctant to label young children in such ways. There are, however, stable individual differences in compassionate and destructive behaviors which are present early in development (Cummings et al., 1986). We need to understand these differences, using some of the more expanded conceptualizations and sophisticated research methods now available for studying the roles of both temperament and environment in the development of empathy. Otherwise, more ideologically based positions for which there is no strong scientific evidence will go untested. This includes arguments that humans are genetically programmed to be more altruistic toward blood relatives and also toward others who are physically like themselves than to individuals who are biologically dissimilar (Rushton, Russell, \& Wells, 1984).

\section{CONCLUSIONS}

We have focused on the second year of life, because it is a critical period for the development of empathic, prosocial behavior patterns and for important aspects of social competence more generally. It has been identified in major social-cognitive (e.g., Piaget, 1965) and psychodynamic (e.g., Mahler, Pine, \& Berman, 1975) developmental theories as a time when both increased symbolic abilities and emotional maturity allow for both greater self-development and increased appreciation of others as individuals. Within an organizational perspective (Cicchetti \& SchneiderRosen 1986), it is a time period when self-regulation and modulation of impulses and emotions begin to occur. Given optimal environmental conditions, most children would be expected to go through a normative transition from more aroused to more modulated patterns of empathic responding.

However, in nonoptimal and atypical environments, children may experience early arrests or delays that result in different developmental pathways. For example, they may be maintained in states of overarousal by needy caregivers, or guided toward callous behavior patterns by hostile and indifferent caregivers, or forced to suppress tenderness by adults who view sensitivity as a sign of weakness. Children exposed to these different socialization experiences would be likely to approach subsequent developmental tasks pertaining to connection and commitment from quite different perspectives, i.e., they would have quite different working models of what it means to care for others and to be cared for by them. We do not yet know how easy or difficult it is to alter stable patterns or styles of responding. Nor do we know much about why some children are particularly vulnerable or resilient to negative environmental conditions that influence 
empathic patterns. Who are the children who fail to develop compassion for others, even under optimal environmental conditions? At what point do disturbances in empathic patterns begin to reflect "markers" of specific psychopathologies? We know autistic children suffer from biologically based deficits that interfere with social-emotional communication and establishing caring connections. Are there other constitutionally based differences, e.g., of temperament or of information processing difficulties that lead to very early disruptions in the development of empathy? Some children with learning disabilities, for example, have problems interpreting social cues and "reading" others' emotions. Such deficits may make it difficult to arrive at an accurate, clear understanding of what other individuals experience and how they function.

This "trait" approach to empathy derives from an effort to understand stable patterns of individual differences over time and contexts (Cummings et al., 1986). It is recognized that empirical evidence for such a trait is modest, that there may be many situational determinants of empathy, that there are multiple forms of empathy, and that contexts may sometimes overwhelm individual patterns of variation and produce uniformities across individuals. We do know, however, that from an early age children differ markedly in their capacity to reach out to others in need.

In attempting to understand individual differences, we have raised questions about the conceptualization and measurement of empathy. Is it possible to reduce empathy to a matching or near matching of affective responses that reflects either personal distress or sympathetic distress? Feelings of personal distress and sympathy may not necessarily be inversely related and may even be positively correlated (Fabes, Eisenberg, \& Miller, 1990). It may not always be the case that heart rate acceleration represents empathy transformed into personal distress, or that heart rate deceleration in the face of suffering in others reflects sympathy. There are circumstances under which heart rate deceleration could reflect only interest in the suffering, as well as cases in which heart rate acceleration could reflect sympathetic distress. With regard to the latter, in a study by Wiesenfeld, Whitman, and Malatesta (1984), high physiological arousal in response to infant cries (evidence, in part, by high heart rate) was associated with empathic behavior patterns. And work with preschool children suggests that those most likely to help others tend themselves to cry more often (i.e., they are arousable children) (Howes \& Parver, 1987).

Coding of discrete emotions does not lead to unambiguous interpretations of empathy and the form it eventualiy takes. In some systems, sadness in response to another's distress is seen as a potential indicator of empathy that should support prosocial behavior. In theories of emotional development, however (Campos et al., 1983), sadness is viewed as 
an emotion that leads to withdrawal, turning inward, and shutting down. Clearly, the intensity of the affective experience plays an important role here. Also, more information is needed about the intentions and motives of the individual, and the instigating conditions of the moment and across time.

For most of the children we have studied in the second year of life, affective arousal becomes more modulated and is sometimes transformed into caring actions that appear to have as their ultimate goal alleviating the suffering of others. Feelings of concern and compassion do not require action, any more than prosocial behaviors automatically imply sympathic concern. But positive actions that accompany or follow expressions of concern do help us to infer children's underlying motives and goals. Interconnections between affect, cognitions and prosocial behaviors, all reflecting concern for the other, are very much in evidence early in development. And purposive, goal-oriented sympathetic actions appear to evolve directly from the more reflexive, automatic patterns of arousal. Because sympathetic distress evolves from personal distress (and possibly from a need to reduce aversive arousal), there may remain, throughout development, a complex, fluid interrelatedness of concern for self and concern for other. This concern for self is quite different from the more callous self-centeredness that reflects indifference and insensitivity to the plights of others (which we would view as the "opposite" to empathy/ sympathy).

Batson and Shaw (in press) draw a sharp distinction between reflexive vs. goal-oriented actions that benefit another. In their view, while goal-oriented prosocial actions may be empathically-based, reflexive actions can not. If the caring response is automatic, it does not qualify as "true" empathy. An alternative view, grounded in a developmental approach, recognizes a continuum or possible gradation from relatively more reflexive to relatively more purposeful empathic patterns, and, moreover, the possibility that the latter could derive from the former. In maintaining a dichotomy between reflexive and goal-oriented actions, the evolutionary significance of concern for others across species and time is ignored. Also ignored is the possibility that different types of empathy may evolve early in development.

Often in research sharply drawn distinctions are made and for good reasons: They aid in the development of clear, concise conceptualizations and operational definitions of research constructs. But sometimes this results in the construction of dichotomies that represent oversimplifications of issues and erode the essence of the phenomena under exploration. Perhaps we should not continue to ask whether we are egoistic or altruistic; or whether empathic patterns reflect either personal distress or sympathetic 
distress; or whether our caring actions are reflexive or goal-oriented patterns; or whether only goal-oriented prosocial patterns qualify as truly altruistic; or whether empathic, caring actions that occur in the context of caregiving ever qualify as altruistic; or whether empathy toward the young is always ultimately selfish, because it helps to perpetuate the biological self.

It may be more fruitful to ask what are the conditions of development, temperament, family life, socialization, and culture that influence the diverse ways in which self-concern and concern for others are expressed and balanced within different individuals. The focus on whether we are solely egoistic or both egoistic and caring individuals has been very entrenched and has shifted attention away from important questions about individual differences. There is a need to know more about the processes that permit a forging of connections within and across families, cultures, and nations. Both research and cumulative wisdom indicate that individuals vary markedly in their capacities to establish these empathic ties. Additional work is needed to learn more about the origins of both self-preservation and commitment to others, and their delicate and complex interplay.

\section{REFERENCES}

American Psychiatric Association (1987). Diagnostic and statistical manual of mental disorders (3rd ed., revised).. Washington, DC: Author.

Amsterdam, B. (1972). Mirror self-image reactions before age two. Developmental Psychology, $8,297-305$.

Barnett, M. A., McMinimy, V., Flouer, G., \& Masbad, I. (1987). Adolescent's evaluations of peers' motives for helping. Journal of Youth and Adolescence, 16, 579-586.

Batson, C. D., Batson, J. G., Griffitt, C. A., Barrientos, S., Brandt, J. R., Spreugelmeyer, P. \& Bayly, M. J. (1989). Negative-state relief and the empathy-altruism hypothesis. Journal of Personality and Social Psychology, 56, 922-933.

Batson, C. D., Dyck, J. L., Brandt, J. R., Batson, J. G., Powell, A. L., McMaster, M. R., \& Griffith, C. A. (1988). Five studies testing two new egoistic alternatives to the empathy-altruism hypothesis. Joumial of Personality and Social Psychology, 55, 52-77.

Batson, C. D., \& Shaw, L. L. (in press). Evidence for altruism: Toward a pluralism of prosocial motives. Psychology Inquiiry.

Beardslee, W., \& Podorefsky, D. (1988). Resilient adolescents whose parents have serious affective and other psychiatric disorders: Importance of self-understanding and relationships. American Joumal of Psychiatry, 145, 63-69.

Beardslee, W. R., Schultz, L. H., \& Selman, R. L.. (1987). Level of social-cognitive development, adoptive functioning and DSM-III diagnoses in adolescent offspring of parents with affective disorders: Implications for the development of the capacity for mutuality. Developmental Psychology, 23, 807-815.

Bertenthal, B. I., \& Fischer, K. W. (1978). the development of self-recognition in the infant. Developmental Psychology, 14, 44-50.

Bloom, L., P., \& Hood, L. (1975). Structure and variation in child language. Monographs of the Society for Research in Child Development, 40 (3-4, serial no. 161). 
Bretherton, I., Fritz, J., Zahn-Waxler, C., \& Ridgeway, D. (1986). The acquisition and development of emotion language: A functionalist perspective. Child Development, 57 , 529-548.

Brothers, L. (1989). A biological perspective on empathy. The American Journal of Psychiatry, $146,10-19$.

Bruner, J. S. (1972). The nature and uses of immaturity. American Psychologist, 27, 1-22.

Butterworth, G. (1980). A discussion of some issues raised by Piaget's concept of childhood egocentrism. In M. V. Cox (Ed.), Are young children egocentric? (pp. 17-40). York, England: Batsford Academic and Educational.

Campos, J. J., Barrett, K. C., Lamb, M. E., Goldsmith, H. H., \& Stenberg, C. (1983). Socio-emotional development. In P. H. Mussen (Ed.), Handbook of child psychology (4th ed., pp. 783-915) New York: Wiley.

Caplan, M. Z., \& Hay, D. F. (1989). Preschoolers' responses to peers' distress and beliefs about bystander intervention. Joumal of Child Psychology and Psychiatry, 30, 231-242.

Carlson, M., \& Miller, N. (1987). Examination of the relation between negative mood and helping. Psychological Bulletin, 102, 91-108.

Cialdini, R. B., Schaller, M., Houlihan, D., Arps, K., Fultz, J., \& Beaman, A. L. (1987). Empathy-based helping: Is it selflessly motivated? Joumal of Personality and Social Psychology, 52, 749-758.

Cicchetti, D., \& Schneider-Rosen, K. (1986). An organizational approach to childhood depression. In M. Rutter, C. Izard, \& P. Read (Eds.), Depression in young people: Clinical and developmental perspectives. New York: Guilford Press.

Cohn, J. Fs, \& Tronick, E. Z. (1983). Three-month-old infants' reaction to simulated matemal depression. Child Development, 54, $185-193$.

Cohn, J. K., Campbell, S. B., Matias, R., \& Hopkins, J. (1990). Face-to-face interactions of postpartum depressed and non-depressed mother-infant pairs at 2 months. Developmental Psychology, 26, 15-23.

Cooley, C. H. (1926). The roots of social knowledge. American Joumal of Sociology, 32, 59-79.

Cummings, E. M., Hollenbeck, B., Iannotti, R., Radke-Yarrow, M., \& Zahn-Waxler, C. (1986). Early organization of altruism and aggression: Developmental patterns and individual difference. In C. Zahn-Waxler, E. M. Cummings, \& R. Iannottì (Eds.), Altruism and aggression: Biological and social onigins (pp. 165-188). New York, London, \& Cambridge: Cambridge University Press.

Cummings, E. M., Zahn-Waxler, C., \& Radke-Yarrow, M. (1981). Young children's responses to expressions of anger and affection by others in the family. Child Development, 52, $1274-1282$.

Cummings, E. M., Zahn, Waxler, C., \& Radke-Yarrow, M. (1984). Developmental changes in children's reactions to anger in the home. Joumal of Child Psychology and Psychiatry and Allied Disciplines, 25, 63-74.

Danwin, C. (1872). The expression of the emotions in man and animal. London: John Murray.

Dawkins, R. (1976). The selfish gene. Oxford, England: Oxford University Press.

Eckerman, C. O., Whatley, J. L., \& Kutz, S. L. (1975). Growth of social play with peers during the second year of life. Developmenial Psychology, 11, 42-49.

Eisenberg, N., \& Lennon, R. (1980). Altruism and the assessment of empathy in the preschool years. Child Development, 51, 552-557.

Eisenberg, N., Fabes, R. A., Miller, P. A., Fultz, J., Shell, R., Mathy, R. M., \& Reno, R. R. (1989a). Relation of sympathy and personal distress to prosocial behavior: $A$ multi-method study. Joumal of Personality and Social Psychology, 57, 55-66.

Eisenberg, N., Fabes, R. A., Shaller, M., \& Miller, P. A. (1989b) Sympathy and personal distress: Development, gender differences, and interrelations of indexes. In N. Eisenberg (Ed.), Empathy and related emotion responses (New Directions in Child Development, No. 44, pp. 107-126). San Francisco: Jossey-Bass.

Eisenberg, N., \& Strayer, J. (1987). Empathy and its development. Cambridge, England, \& New York: Cambridge University Press.

Emde, R., Johnson, W., \& Easterbrooks, M. A. (1987). The do's and don'ts of early moral development: Psychoanalytic tradition and current research. In J. Kagan, \& S. Lamb 
(Eds.), The emergence of morality in young children (pp. 245-276). Chicago: University of Chicago Press.

Emery, R. E. (1982). Interparent conflict and the children of discord and divorce. Psychological Bulletin, 92, 310-330.

Fabes, R. A., Eisenberg, N., \& Miller, P. (1990). Maternal correlates of children's vicarious emotional responsiveness. Developmental Psychology, 26, 639-648.

Field, T., Woodson, R., Greenberg, R., \& Cohen, D. (1982). Discrimination and imitation of facial expressions by neonates. Science, 218, 179-181.

Freud, S. (1958). Civilization and its discontents. New York: Doubleday Anchor Books.

Gladstein, G. A. (1984), the historical roots of contemporary empathy research. Joumal of the History off the Behavioral Sciences, 20, 38-59.

Haviland, J. M., \& Lelivica, M. (1987). The induced affect response: 10-week-old infants' responses to three emotion expressions. Developmental Psychology, 23, 97-104.

Haynes-Seman, C. (1987). Developmental origins of moral masochism: A failure-to-thrive toddler's interactions with mother, Child Abuse and Neglect, 11, 319-330.

Hoffman, M. L. (1975). Developmental synthesis of affect and cognition and its interplay for altruistic motivation. Developmental Psychology, 11, 607, 622.

Hoffman, M. (1982). Development of prosocial motivation: Empathy and guilt. In N. Eisenberg (Ed.), The development of prosocial behavior (pp. 281-313). New York: Academic Press.

Howes, C., \& Eldridge, R. (1985). Responses off abused, neglected and nonmaltreated children to the behaviors of their peers. Journal of Applied Developmental Psychology, 6, 261-270.

Howes, C., \& Parver, J. (1987). Toddlers' responses to the distress of their peers. Joumal of applied Developmental Psychology, 8, 441-452.

Izard, C. E. (1977). Human emotion. New York: Plenum Press.

Kagan, J., \& Lamb, S. (1987). The emergence of morality in young children. Chicago: University of Chicago Press.

Klimes-Dougan, B., \& Kistner, J. (1990). Physically abused preschoolers' responses to peers' distress. Developmental Psychology 26, 599-602.

Koestner, R., Franz, C., \& Weinberger, J. (1990). The family origins of empathic concern: A 26-year longitudinal study. Journal of Personality and Social Psychology, 58, 709-717.

Lewis, M., Sullivan, M., Stanger, C., \& Weiss, M. (1989). Self development and self-conscious emotions. Child Development, 60, 146-156.

MacLean, P. D. (1985). Brain evolution relating to family, play, and the separation call. Archives of General Psychiatry, 42, 405-417.

Mahler, M. S., Pine, F., \& Bergman, A. (1975). The psychological birth of the human infant: Symbiosis and individuation. New York: Basic Books.

Main, M., \& George, C. (1985). Response of abused and disadvantaged toddlers to distr ss in playmates: A study in the day care setting. Developmental Psychology, 21, 407-412

Main, M., \& Goldwyn, R. (1984). Predicting rejection of her infant from mother's representation of her own experience: Implications for the abused-abusing intergenerational cycle. Child Abuse and Neglect. 8, 203-217.

Matas, L., Arend, R. A., \& Sroufe, L. A. (1978). Continuity of adaptation in the second year: The relationship between quality of attachment and later competence. Child Development, $49,547-556$.

Mathews, K. A., Batson, C. D., Horn, J., \& Rosenman, R. H. (1981). Principles in his nature which interest him in the fortune of others: The heritability of empathic concern for others. Joumal of Personality, 49, 237-247.

McCall, R. B. (1979). Qualitative transitions in behavioral development in the first three years. In M. H. Bornstein \& W. Kessen (Eds.), Psychological development in infancy. New York: Erlbaum.

Mead, C. H. (1934). Mind, self and society. Chicago: University of Chicago Press.

Meltzoff, A. N., \& Moore, M. K. (1977). Imitation of facial and manual gestures by human neonates. Science, 198, 75-78. 
Miller, P. A., \& Eisenberg, N. (1988). The relation of empathy to aggressive and externalizing/antisocial behavior. Psychological Bulletin, 103, 324 344.

Nicolich, L. (1977). Beyond sensorimotor intelligence: Assessment of symbolic maturity through analyses of pretend play. Merrilt-Palmer Quarterly, 23, 89-99.

Piaget, J. (1962). Play, dreams and imitation in childhood. New York: Norton.

Piaget, J. (1965). The moral judgment of the child. New York: Harcourt, Brace. (Original work published in 1932).

Radke-Yarrow, M., \& Zahn-Waxler, C. (1976). Dimensions and correlates of prosocial behavior in young children. Child Development, 47, 118-125.

Radke-Yarrow, M., \& Zahn-Waxler, C. (1984). Roots, motives, and patterning in children's prosocial behavior. In E. Staub, K. D. Bartal, J. Karylowski, \& J. Raykowski (Eds.), The development and maintenance of prosocial behavior: Intemational perspectives on positive morality. New York: Plenum Press.

Radke-Yarrow, M., Zahn-Waxler, C., \& Chapman, M. (1983). Children's prosocial dispositions and behavior. In P. H. Mussen, \& E. M. Hetherington (Eds.), Handbook of child psychology: Socialization, personality, and social development (Vol. 4, pp. 469-545), New York: Wiley.

Rheingold, H. L., \& Emery, G. N. (1986). The nurturant acts of very young children. In D. Olweus, J. Block, \& M. Radke-Yarrow (Eds.), The development of anti-and prosocial behavior. New York: Academic Press.

Rheingold, H., Hay, D., \& West, M. (1976), Sharing in the second year of life. Child Development, 47, 1148-1158.

Ross, H. S., \& Goldman, B. D. (1977). Establishing new social relations in infancy. In T. Alloway, L. Kramer, \& P. Plinerf (Eds.), Advances in the study of communication and affect: Vol. 3. Attachment behavior. New York: Plenum Press.

Rushton, J. P., Fulker, D. W., Neale, M. C., Nias, D. L. B., \& Eysenck, H. J. (1986). Altruism and aggression: The heritability of individual differences. Joumal of Personality and Social Psychology, 50, 1192-1198.

Rushton, J. P., Russell, R. J. H., \& Wells, P. A. (1984). Genetic similarity theory: Beyond kin selection. Behavior Genetics, 14, 179-193.

Sagi, A., \& Hoffman, M. L. (1976). Empathic distress in the newborn. Developmental Psychology, 12, 175-176.

Shott, S. (1979). Emotion and social life: A symbolic interactionist analysis. American Journal of Sociology, 84, 1317-1334.

Simner, M. L. (1971). Newborn's responses to the cry of another infant. Developmental Psychology, 5, 136-150.

Stern, D. (1985). The interpersonal world of the infant. New York: Basic Books.

Stipek, D. J., Gralinski, J. H, \& Kopp, C. B. (1990). Self-concept development in the toddler years. Developmental Psychology, 26, 972-977.

Strayer, J., \& Roberts, W. (1989). Children's empathy an role taking: Child and parental factors and relations to prosocial behavior. Joumal of Applied Developmental Psychology, $10,227-239$.

Sullivan, H. S. (1947). Conceptions of modern psychiatry. Washington, DC: White Foundation.

Termine, N. T., \& Izard, C. E. (1988). Infants' responses to their mothers' expressions of joy and sadness. Developmental Psychology, 24, 223-229.

Teti, D. M., \& Ablard, K. A. (1991). Security of attachment and infant-sibling relationships: A taboratory study. Child Development.

Trevarthen, C. (1989). Origins and directions for the concept of infant intersubjectivity. Society for Research in Child Development, Newsletter.

Watson, M., \& Fischer, K. (1977). A developmental sequence of agent use in late infancy. Child Development, 48, 828-836.

Weisenfeld, A. R., Whitman, P. B., \& Malatesta, C. Z. (1984). Individual differences among adult women in sensitivity to infants: Evidence in support of an empathy construct. Joumal of Personality and Social Psycholog, 46, 118-124.

Wilson, E. O. (1975). Sociobiology: The new synthesis. Cambridge, MA: Harvard University Press. 
Yarrow, M., Scott, P., \& Waxler, C. (1973). Learning concern for other. Developmental Psychology, 8, 240-260.

Zahn-Waxler, C. Cole, P., \& Barrett, K. C. (1991). Guilt and empathy: Sex differences and implications for the development of depression. In K. Dodge \& J. Garber (Eds.), Emotion regulation and dysregulation. New York: Cambridge University Press.

Zahn-Waxler, C., \& Kochanska, G. (1990). The origins of guilt. In R. Thompson (Ed.), Socioemotional development (pp. 183-258. Lincoln: Nebraska Symposium on Motivation, University of Nebraska Press.

Zahn-Waxler, C., Kochanska, G. Krupnick, J., \& McKnew, D. (1990). Patterns of guilt in children of depressed and well mothers. Developmental Psychology, 26, 51-59.

Zahn-Waxler, C., \& Radke-Yarrow, M. (1982). The development of altruism: Alternative research strategies. In N. Eisenberg (Ed.), The development of prosocial behavior (pp. 109-137). New York: Academic Press.

Zahn-Waxler, C. Radke-Yarrow, M., \& King, R. A. (1979). Child-rearing and children's prosocial initiations toward victims of distress. Child Development, 50, 319-330.

Zahn-Waxler, C., Radke-Yarrow, M., Chapman, M., \& Wagner, E. (1990). The development of concern for others. Unpublished manuscript.

Zahn-Waxler, C., Robinson, J., \& Emde, R. (1991). The development and heritability of empathy. Poster presentation, Society for Reseach in Child Development, Seattle, WA, April.

Zahn-Waxler, C., \& Smith, K. D. (in press). The development of prosocial behavior. In V. B. Van Hasselt and M. Herson (Eds.), Handbook of Social Development: $A$ lifespan perspective, New York: Plenum Press. 